\title{
Influence of type of dwellings on the prevalence of chronic respiratory diseases in Ho Chi Minh City, Viet Nam
}

\author{
T. N. Tran, ${ }^{1,2}$ N. B. $\operatorname{Tran}^{1}{ }^{1}$ H. M. T. Tran, ${ }^{1}$ H. K. Tang, ${ }^{1}$ X. M. Ngo, ${ }^{1}$ I. Godin, $^{2}$ O. Michel, ${ }^{3}$ C. Bouland ${ }^{2}$ \\ ${ }^{1}$ Pham Ngoc Thach University of Medicine, Ho Chi Minh City, Viet Nam; ${ }^{2}$ School of Public Health, Universite Libre \\ de Bruxelles (ULB), Brussels, ${ }^{3}$ Centre Hospitalier Universitaire Brugmann, ULB, Brussels, Belgium
}

SUM M ARY

SETTING AND OBJECTIVE: Exposure to pollutants is related to the type of dwelling inhabited. Besides tobacco smoke, indoor air pollution is a significant risk factor for chronic respiratory disease (CRD). The prevalence of CRD by type of dwelling was studied in Ho Chi Minh City, Viet Nam.

DESIGN: A total of 1561 people living in four type of dwellings were enrolled. Information on respiratory health, lung function, dwelling characteristics and sources of indoor pollution was obtained using a symptom and demographics questionnaire and spirometry. The two main respiratory health outcomes were clinical chronic CRD (CCRD) and chronic obstructive respiratory disease (CORD) (forced expiratory volume in $1 \mathrm{sec} /$ forced vital capacity <0.7). We used binary logistic regression adjusted for age, sex, time spent at home, smoking status, certain occupational exposures, previous tuberculosis, presence of pets, rats or cockroaches at home, wall dampness, biofuel use and use of airconditioning. RESULTS: The prevalence of CCRD (24.3\%) and CORD $(5.3 \%)$ in the type of dwellings studied were not similar $\left(\chi^{2} P<0.0001\right)$. CCRD and CORD prevalence was similar in tube houses and apartments. Compared to people living in apartments, those living in rental single rooms had a $46 \%$ higher risk of developing CCRD. The odds ratio of having CORD in people living in rental single rooms and in rural houses were respectively $4.64(95 \% \mathrm{CI} 1.97-10.5)$ and $2.99(95 \% \mathrm{CI}$ 1.21-7.37).

CONCLUSION: Type of dwelling was associated with CCRD and CORD morbidity.

KEY WORDS: CORD; type of dwelling; spirometry; asthma; chronic obstructive pulmonary disease; respiratory symptoms
RECENT STUDIES INDICATE that indoor air pollution is a key environmental risk factor contributing to the burden of chronic respiratory disease (CRD). ${ }^{1-7}$ Asthma and chronic obstructive pulmonary disease (COPD), the most common CRDs, are diagnosed using symptoms and spirometry. ${ }^{8,9}$ Beside tobacco smoke, indoor and outdoor pollution, certain occupational exposures and post-tuberculosis lung damages play an important role in causing and exacerbating CRD, particularly in countries experiencing rapid economic growth, such as Viet Nam. ${ }^{10}$

Individual behaviours and dwelling characteristics are important modifiers of the degree of exposure to indoor pollutants. Housing characteristics, such as type of construction, wall dampness and ventilation, can affect the accumulation of pollutants. ${ }^{11,12}$ Viet Nam and other South East Asian countries have a large diversity of types of dwellings. Ho Chi Minh City, the largest city in Viet Nam, has recently been experiencing rapid urbanisation and has many types of houses. Only a few studies have analysed the potential influence of the type of dwelling on CRD prevalence. In China, Gan et al. observed that inhabitants of apartments had fewer chronic respiratory symptoms than inhabitants of other type of dwellings. ${ }^{13}$

We hypothesised that the diversity in the type of dwelling in Viet Nam could lead to differences in CRD prevalence. We aimed to compare CRD prevalence among people residing in different types of accommodation to investigate if the differences could be attributed to type of dwelling.

\section{MATERIALS/METHODS}

Site selection and participant recruitment

In 2016, a cross-sectional study was conducted in 24 districts of Ho Chi Minh City among 506 people residing in four different types of accommodation: apartments, rental single rooms, rural houses and tube houses. ${ }^{14}$

The selection and validation of type of dwellings method has been previously reported. ${ }^{14}$ Each type of house was identified based on visual inspection as

Correspondence to: Thanh Ngoc Tran, Pham Ngoc Thach University of Medicine, 78/2 Tran Nhan Ton Street, District 10, Ho Chi Minh City, Viet Nam. email: dr.tranngocthanh@pnt.edu.vn

Article submitted 22 January 2019. Final version accepted 8 August 2019. 
follows: apartments resembled apartments in the West (one of a set of large rooms in a building with some rooms inside, windows and a main entrance); tube houses were narrow, long and built close together in buildings with several floors; rental single rooms were small ground floor rooms with poor ventilation, frequently with no flush toilets and a kitchen in the main living area; rural houses were separate houses built of wood or semi-solid materials found in rural and suburban districts with no flush toilets.

Assuming a general population CRD prevalence of $15 \%$ (including $6 \%$ CRD among non-smokers), a sample of at least 300 individuals per type from 150 rental single rooms, 40 rural houses, 75 apartments and 75 tube houses was recruited. ${ }^{15}$ Five districts (one rural, one suburban and three urban) were selected using cluster sampling. Houses were selected in each district using World Health Organization's 30-cluster sampling method. ${ }^{16}$ All people without contraindication of spirometry were invited to participate.

Approval was obtained from of the ethical committee of the Pham Ngoc Thach University of Medicine, Ho Chi Minh City, Viet Nam (code: CS.2015.04)

The selection and validation of the type of dwellings method has been previously reported. ${ }^{14}$

\section{Materials, data collection and bias control Questionnaire}

We used a questionnaire comprising questions on demographics, socio-economic and occupational status, smoking habits, dwelling characteristics, respiratory symptoms and severity of breathlessness. Cumulative smoking was estimated in pack-years by multiplying the number of cigarette packs smoked per day and the number of smoking years. The level of exercise-induced dyspnoea severity was determined according to the modified British Medical Research Council (mMRC) scale of 0 to $4 .{ }^{9}$ The questionnaire was adapted from the American Thoracic Society (ATS), Europe Respiratory Society (ERS) and International Primary Care Respiratory Group guidelines. ${ }^{17}$

\section{Spirometry}

Spirometry was performed using a micro-loop spirometer (Care Fusion, BD, Sparks, MD, USA) to measure forced expiratory volume in $1 \mathrm{sec}\left(\mathrm{FEV}_{1}\right.$, expressed in L), forced vital capacity (FVC, in L) and vital capacity (VC, in L) using ATS and ERS criteria. ${ }^{18}$ The minimum requirement was to achieve at least two repeatable forced expirations (i.e., difference of $<200 \mathrm{~mL}$ between two FVC and $\mathrm{FEV}_{1}$ measures) and $\geq 6 \mathrm{sec}$ exhalation. ${ }^{19}$ Spirometry was conducted without the bronchodilator response test. The spirometer was calibrated before each day of measurement with a $3 \mathrm{~L}$ standard pump (Care
Fusion). Predicted values are based on references for the Asian population. ${ }^{20}$

\section{Definition of outcomes}

The two main outcomes of this study were clinical CRD (CCRD) and confirmed obstructive respiratory disease (CORD). CCRD was defined as the presence of at least one symptom of CRD (chest tightness, cough, dyspnoea and wheezing in the last 12 months. CORD was defined as $\mathrm{FEV}_{1} / \mathrm{FVC}<0.70$ (or 0.75 ) in adults and $<0.9$ in children. ${ }^{8,9}$ CORD only includes asthma and COPD being characterized by airway obstruction while CCRD consists of a larger group of CRDs. ${ }^{10}$

\section{Statistical methods}

Types of dwelling and patient characteristics were compared and correlations between obvious variables (previous tuberculosis, respiratory symptoms, CCRD, CORD and mMRC levels) and each studied outcome were determined using the $\chi^{2}$ and the $t$-tests. Variables associated with each outcome were entered into a binary regression model. Odds ratios (ORs) and $95 \%$ confidence intervals (CIs) were calculated for exposure to risk factor adjusted for covariables using the Stepwise Method and the Enter Method. The adjusted covariates were age, sex, body mass index, education level, smoking level, presence of pets and cockroaches at home, damp walls, airconditioning, biomass use and time spent at home. Definitions, categories and the selection method used for covariates are given in the Supplementary Data. $P=0.05$ was considered significant. All data were analysed using SPSS v22.0 (IBM Corp, Armonk, NY, USA).

\section{RESULTS}

\section{Population characteristics}

Characteristics of 1561 participants from 506 homes are shown in Supplementary Table S1. CORD prevalence was $5.3 \%$ and CCRD prevalence was $24.3 \%$. There were 118 participants $(7.6 \%)$ with specific physician-diagnosed CRDs. Among participants with a cumulative smoking of $<10$ pack-years, CORD and CCRD prevalences were respectively $4.2 \%$ and $23 \%$.

Characteristics of accommodation and inhabitants by type of dwelling are given in Supplementary Table S2. People living in rural houses were older, more frequently woman, with a lower education level and often used biofuels and burned incense; they also spent more time in home. Residents of rural houses were also more likely to have pets, rats and damp walls. People living in rental single rooms had a higher occupational risk, but were less likely to burn incense or have pets than those living in other type of dwellings. To note, cumulative smoking among 
residents of the four types of accommodation was not statistically different.

\section{CRD prevalence by type of dwelling}

The prevalence of CRD symptoms, CCRD, CORD and the mMRC score were significantly higher among people living in rural houses or rental single rooms than among those living in tube houses or apartments; the prevalence of past tuberculosis was similar among residents living in all type of dwellings (Supplementary Table S3). Non-smokers or smokers with $<10$ pack-years had similar results (Supplementary Table S4).

After adjusting for all related factors, the ORs of symptoms, CCRD, CORD and the mMRC score were calculated by type of dwelling (Supplementary Table S5). Compared to people living in apartments, those living in rental single rooms (both smokers with $<10$ and $>10$ pack-years) were at higher risk of having clinical symptoms and CCRD or CORD. Compared to people living in apartments, those in rural houses (both smokers with $<10$ and $>10$ packyears) was at higher risk of CORD, while the risk of having clinical symptoms (except dyspnoea) was not significantly different. The risk of having respiratory symptoms and diseases were comparable in tube houses and apartments. The use of spirometry measures allowed to highlight the higher risks related to airway obstruction in those living in rental single rooms and in rural houses that had not been singularized using symptoms alone (higher OR). We observed, comparing rental single rooms and rural houses with apartment, respectively a 1.46-fold and 0.99 -fold of the odds of CCRD (diagnosed based on study questionnaire) and a 4.64-fold and 2.99-fold of

?1 odds of CORD (diagnosed by spirometry).

\section{DISCUSSION}

We assessed the effect of dwelling type on CRD prevalence. We observed that the type of residence plays a role in the development of CRD. Using a large sample, we first examined CRD prevalence in the general population and then by type of dwelling in Ho Chi Minh City. Both clinical symptoms and spirometry were used to identify CRD cases and obtain better understanding of the correlation between CRDs and type of dwelling.

\section{CRD prevalence by type of residence}

CCRD rates in the general population as determined using questionnaires across some developing countries (Argentina, 32.2-36\%; Nepal, 11.3-17.1\%; Thailand $8.4-9.8 \%$ ) were reported to be lower than our findings $(24.3 \%) .{ }^{21}$ CORD prevalence, as determined using spirometry, was $5.3 \%$ in our study, while it varies from $<5 \%$ among females in the Philippines, Estonia and Tunisia to $>20 \%$ among males in South
Africa and Australia. ${ }^{10}$ This rate increases with increase in the mean number of smoking pack-years per inhabitant.

As the rate of diagnosed CRD in the general population was much lower than the prevalence of CCRD, it may be hypothesised that many people were delaying their early CRD control opportunity. The difference between the prevalence of physician diagnosed CRD $(7.6 \%)$ and the CCRD rate $(24.3 \%)$ based on questionnaire responses on symptoms suggests that some patients may have had CRD for a prolonged period of time before seeking care. An earlier study showed that only $2 \%$ of asthma patients are diagnosed in Viet Nam, while this was 33\% in Australia. ${ }^{10}$

The prevalence of CCRD (determined using a symptom questionnaire) was higher than that of CORD (determined using spirometry). As people experiencing mild dyspnoea do not always report symptoms, respiratory disease can only be detected on spirometry, while those with more serious disease experience are likely to experience more severe symptoms. ${ }^{8,9}$ As both symptom screening and spirometry were used in this study, we were able to obtain a more accurate estimate of CRD prevalence. Spirometry measures indicated a higher risk of developing CORD among people living in rental single rooms and rural houses than among those living in apartments and tube houses. Based on an evaluation of clinical symptoms, we found that only people living in rental single rooms are at a higher risk of CCRD. Thus, people living in rental single rooms are at higher risk of COPD and asthma than those living in other types of dwellings, as determined using both spirometry and clinical symptoms.

\section{The relationship between type of dwelling and CRD prevalence}

CCRD prevalence $(23 \%)$ and CORD prevalence $(4.2 \%)$ were high even among light smokers. This suggests that the indoor environment could be an important risk factor for CRD. Nhung et al. reported that the incidence of COPD among non-smokers in Viet Nam is estimated to be $6 \% .15$

It is known that the association of CRD and indoor pollution could be due to the use of biofuels. ${ }^{1}$ However, we believe that the type of building and quality of ventilation could also play a role. In our study, type of dwelling was a factor associated with CCRD, CORD and the severity of dyspnoea in both the general population and in light smokers. The fact that smoking status and the history of tuberculosis among residents of different type of dwellings were similar suggests that the type of dwelling can influence CRD prevalence. Exposure to indoor pollutants depends on both the behaviour of inhabitants (in emitting pollutants) and on the quality of the ventilation system (in reducing pollutants). The latter plays an important role in reducing the concentration 
of indoor pollutants. ${ }^{22}$ Poor ventilation could lead to the accumulation of pollutants that would increase the risk of developing CRD. Availability of proper ventilation could then influence the distribution of CRD in the population. ${ }^{23,24}$ The association between ventilation, CRD and indoor pollution have been reported in previous studies, ${ }^{1,25}$ but not many studies on the role of the type of dwelling have been published. In our study, the type of dwelling was one of the factors associated with CRD. A recent study also found difference in respiratory health outcomes among residents of different types of dwelling. ${ }^{13}$

\section{Residents of rental single rooms and rural houses were} at higher risk of CRD

People residing in rental single rooms and rural houses had a higher prevalence of CCRD, CORD and severe breathlessness than those living in apartments and tube houses. Gan et al. found that people living in apartments and town houses (comparable to tube houses in our study) had a lower risk of poor respiratory health than those living in mobile homes (comparable to rental single rooms in our study). ${ }^{13}$

Rural houses are common in suburban and rural areas of Ho Chi Minh City. Although this type of dwelling were well-ventilated, more likely to be inhabited by women $(64 \%)$ who were light smokers (91\%), the prevalence of poor respiratory health among residents of rural houses was higher than among those living in apartments and tube houses. Studies have shown that indoor air pollutants and endotoxin levels in rural houses were higher than in other types of dwellings. ${ }^{26,27}$ These factors directly affect lung diseases. ${ }^{1,28,29}$ The greater likelihood of having pets, greater use of biofuels and less use of airconditioning that are more common in rural houses than in other type of dwellings could result in an increase in indoor air pollutants and greater exposure to allergic substances. ${ }^{30-32}$ It also appears that rural houses ventilation are sufficiently wellventilated to reduce the indoor pollutants and endotoxins emitted. Reducing risk factors and improving ventilation should therefore be done simultaneously to prevent CRD development and exacerbation among people living in rural houses.

The problem of ventilation seemed to be significant in rental single rooms. The prevalence of CCRD, CORD and severe breathlessness were clearly higher among rental single room residents than among those living in apartments and tube houses, although demographic and housing characteristics were nearly similar. This difference may be due to the accumulation of indoor pollutants. ${ }^{33}$ The effect of dwelling type was estimated using a regression model including occupational exposures, wall dampness and use of airconditioning. Factors associated with CRDs are more likely to be found in rental single rooms than in other dwelling types. The respiratory health of rental single room residents should therefore be improved.

The risk of developing CRD symptoms, CORD and breathlessness severity did not differ significantly among people living in apartments and those living in tube houses. These types of accommodation are more appropriate in urban areas. Gan et al. also reported that people living in apartments had better respiratory outcomes than those living in other types of dwellings. ${ }^{13}$

In medium and low-income regions where it is not possible to reduce pollution in homes for economic reasons and/or local customs, improving ventilation should be considered as an urgent solution. This would reduce the accumulation of indoor pollutants and prevent CRD, especially among women, children, non-smokers and non-smoker CRD patients. ${ }^{1,25}$

\section{Study limitations}

We used a cross-sectional study with a large sample size to analyse the relationship between type of dwelling and CRD; however, cause and effect relations need to be confirmed using longitudinal studies. Recall bias when responding to the questionnaire may have led to an underestimation of CCRD prevalence. Unlike clinical studies, spirometry measurements in this epidemiological study were carried out without bronchodilator test in the general population. However, we believe that simplified spirometry was appropriate for cost and safety reasons, as this was a screening study. ${ }^{1}$

Our study used both cut-off points for $\mathrm{FEV}_{1} / \mathrm{FVC}$ (i.e., 0.7 and 0.75 ) to obtain a more comprehensive estimate of CORD incidence. Although using the $\mathrm{FEV}_{1} / \mathrm{FVC}<0.75$ cut-off could lead to the detection of more asthma patients, this would include some false-positives. However, the $\mathrm{FEV}_{1} / \mathrm{FVC}<0.7$ cut-off gave a more accurate estimate of airway obstruction than $\mathrm{FEV}_{1} / \mathrm{FVC}<0.75 .^{9}$

The smoking rate $(18.1 \%)$ in participants of this study was lower than in other studies. This was due to the inclusion of participants from a wide age range (10-90 years) and the lack of response (despite several requests) from some smokers who were working. It should be noted that as the rate of smoking was lower due to the large number of smokers, the association between dwelling type and CRD prevalence became more evident. It is wellknown that tobacco smoking is a major cause of CRD and could therefore affect CRD prevalence. Gordon et al. suggested that an appropriate study population with minimal exposure to tobacco smoke could provide more robustevidence for the association between household air pollution and COPD. ${ }^{1}$

\section{CONCLUSION}

People living in rental single rooms had a $46 \%$ higher risk of CCRD and 4.6-fold higher risk of CORD, 
while those living in tube houses had three-fold higher risk than those living in apartments. The risk of developing CCRD and CORD among people living in tube houses and those living in apartments were not statistically significantly different. Changing behaviour and improving ventilation should be done simultaneously. A screening programme should be used for the early detection of CRD because of the large number of individuals who remain undiagnosed in the community.

\section{Acknowledgements}

The study was supported by a Projet Interuniversitaire Ciblé between the Universite Libre de Bruxelles (Brussels, Belgium) and the Pham Ngoc Thach University (Ho Chi Minh City, Viet Nam) from 2012 to 2016 [PIC-CUD 2012-2016] and a Partenariat Interuniversitaire Ciblé (http://www.cud.be/content/view/1013/ 504/lang/) granted by the Académie de Recherche et d'Enseignement Supérieur, Brussels, Belgium.

\section{References}

1 Gordon S B, Bruce N G, Grigg J, et al. Respiratory risks from household air pollution in low and middle income countries. Lancet Respir Med 2014; 2: 823-860.

2 Jiang X-Q, Mei X-D, Feng D. Air pollution and chronic airway diseases: what should people know and do? J Thorac Dis 2016; 8: E31-40.

3 Kim D, Chen Z, Zhou L-F, Huang S-X. Air pollutants and early origins of respiratory diseases. Chronic Dis Transl Med 2018; 4: $75-94$.

4 Guan W-J, Zheng X-Y, Chung K F, Zhong N-S. Impact of air pollution on the burden of chronic respiratory diseases in China: time for urgent action. Lancet 2016; 388: 1939-1951.

5 Li J, Sun S, Tang R, et al. Major air pollutants and risk of COPD exacerbations: a systematic review and meta-analysis. Int J Chron Obstruct Pulmon Dis 2016; 11: 3079-3091.

6 Bloemsma L D, Hoek G, Smit L A M. Panel studies of air pollution in patients with COPD: systematic review and metaanalysis. Environ Res 2016; 151: 458-468.

7 Schiavoni G, D’Amato G, Afferni C. The dangerous liaison between pollens and pollution in respiratory allergy. Ann Allergy Asthma Immunol 2017; 118: 269-275.

8 Global Initiative for Asthma. Global strategy for asthma management and prevention 2017. Bethesda, MD, USA: GINA, 2017: pp 14-24. www.ginaasthma.org

9 Global Initiative for Chronic Obstructive Lung Disease. Global Strategy for the Diagnosis, Management and Prevention of COPD, Global Initiative for Chronic Obstructive Lung Disease (GOLD) 2016. Bethesda, MD, USA: GOLD, 2016. http:// goldcopd.org/ Accessed January 2020.

10 Burney P, Jarvis D, Perez-Padilla R. The global burden of chronic respiratory disease in adults. Int $\mathrm{J}$ Tuberc Lung Dis 2015; 19: 10-20.

11 Taylor J, Davies M, Mavrogianni A, et al. Mapping indoor overheating and air pollution risk modification across Great Britain: a modelling study. Build Environ 2016; 99: 1-12.

12 Fabian P, Adamkiewicz G, Levy J I. Simulating indoor concentrations of $\mathrm{NO} 2$ and PM2.5 in multifamily housing for use in health-based intervention modeling: CONTAM simulation of indoor NO2 and PM2.5. Indoor Air 2012; 22: 12-23.

13 Gan W Q, Sanderson W T, Browning S R, Mannino D M. Different types of housing and respiratory health outcomes. Prev Med Rep 2017; 7: 124-129.

14 Tran T T T, Nguyen T K D, Tran N T, et al. Typology of houses and ventilation characteristics: a case study in Ho Chi Minh City. The $14^{\text {th }}$ International Conference of Indoor Air Quality and Climate. Ghent, Belgium: ISIAQ, 2016: p 125 [Abstract 369].

15 Nguyen Viet N, Yunus F, Nguyen Thi Phuong A, et al. The prevalence and patient characteristics of chronic obstructive pulmonary disease in non-smokers in Vietnam and Indonesia: An observational survey: Non-smoking COPD in Vietnam and Indonesia. Respirology 2015; 20: 602-611.

16 Henderson R H, Sundaresan T. Cluster sampling to assess immunization coverage: a review of experience with a simplified sampling method. Bull World Health Organ 1982; 60: 253-260.

17 Levy M L, Fletcher M, Price D B, et al. International Primary Care Respiratory Group (IPCRG) Guidelines: diagnosis of respiratory diseases in primary care. Prim Care Respir J, 2006; 15: 20-34.

18 Miller M R, Hankinson J L, Brusasco V, et al. Standardisation of spirometry. Eur Respir J 2005; 26: 319-338.

19 Hankinson J L, Eschenbacher B, Townsend M, et al. Use of forced vital capacity and forced expiratory volume in 1 second quality criteria for determining a valid test. Eur Respir J 2015; 45: 1283-1292.

20 Quanjer P H, et al. Multi-ethnic reference values for spirometry for the 3-95-yr age range: the global lung function 2012 equations. Eur Respir J 2012; 40: 1324-1343.

21 World Health Organization. Respiratory care in primary care services-a survey in 9 countries. Geneva, Switzerland: WHO, 2004. http://apps.who.int/iris/bitstream/10665/83959/1/ WHO_HTM_TB_2004.333.pdf Accessed January 2020.

22 Taylor E T, Nakai S. Prevalence of acute respiratory infections in women and children in Western Sierra Leone due to smoke from wood and charcoal stoves. Int J Environ Res Public Health 2012; 9: 2252-2265.

23 Jacobs D E. Environmental health disparities in housing. Am J Public Health 2011; 101 (Suppl 1): S115-S122.

24 Sundell J, Levin H, Nazaroff W W, et al. Ventilation rates and health: multidisciplinary review of the scientific literature. Indoor Air 2011; 21: 191-204.

25 Zhou Y, et al. Lung function and incidence of chronic obstructive pulmonary disease after improved cooking fuels and kitchen ventilation: a 9-year prospective cohort study. PLoS Med 2014; 11: e1001621.

26 Holst G, et al. Determinants of house dust, endotoxin, and $\beta-$ $(1 \rightarrow 3)$-D-glucan in homes of Danish children. Indoor Air 2015; 25: 245-259.

27 Ranabhat C L, et al. Consequence of indoor air pollution in rural area of Nepal: a simplified measurement approach. Front Public Health 2015; 3: 5.

28 Barnig C, et al. Indoor dust and air concentrations of endotoxin in urban and rural environments. Lett Appl Microbiol 2013; 56: $161-167$.

29 Stein M M, et al. Innate immunity and asthma risk in Amish and Hutterite farm children. N Engl J Med 2016; 375: 411-421.

30 Berger I, Schierl R, Ochmann U, et al. Concentrations of dust, allergens and endotoxin in stables, living rooms and mattresses from cattle farmers in southern Bavaria. Ann Agric Environ Med 2005; 12: 101-107.

31 Giovannangelo M, Gehring U, Nordling E, et al. Determinants of house dust endotoxin in three European countries - the AIRALLERG study. Indoor Air 2007; 17: 70-79.

32 Waser M, Schierl M, Von Mutius E, et al. Determinants of endotoxin levels in living environments of farmers' children and their peers from rural areas. Clin Exp Allergy 2004; 34: 389397.

33 Sharma D, Jain S. Impact of intervention of biomass cookstove technologies and kitchen characteristics on indoor air quality and human exposure in rural settings of India. Environ Int 2019; 123: 240-255. 
CONTEXTE et OBJECTIF : L'exposition aux polluants est liée à la typologie des maisons. Outre le tabagisme, la pollution de l'air intérieur est un facteur de risque important de maladies respiratoires chroniques (CRD). La prévalence de la CRD dans différents types de maisons a été étudiée à Hô Chi Minh City, Viet Nam. MÉTHODE: Ont été recensées 1561 personnes vivant dans quatre types de maisons. Des informations sur la santé respiratoire, la fonction pulmonaire, les caractéristiques des habitations et les sources environnementales intérieures ont été obtenues par questionnaire et par spirométrie. Les deux résultats principaux en matière de santé respiratoire étaient les CRD cliniques (CCRD) et les maladies respiratoires obstructives chroniques (CORD) (volume expiratoire maximum seconde/capacité vitale forcée $<0,7)$. Nous avons utilisé une régression logistique binaire ajustée selon l'âge, le sexe, le temps passé à la maison, le tabagisme, le risque professionnel, les antécédents de tuberculose, les animaux domestiques, le rat, le cafard, le mur inondé, l'utilisation de la biomasse et du climatiseur.

RÉSULTATS : La prévalence des CCRD $(24,3 \%)$ et des CORD $(5,3 \%)$ ne se répartit pas de manière égale entre les types de maisons étudiées $\left(P<0,0001, \chi^{2}\right)$. Elle est égale dans les maisons à tube et les appartements. Par rapport aux personnes vivant en appartement, celles qui vivent dans une maison de location avaient un risque accru de $46 \%$ de développer un CCRD. Le quotient de probabilité de CORD pour les personnes vivant dans une maison de location et dans une maison rurale était de 4,64 (IC 95\% 1,97-10,5) et 2,99 (IC 95\% 1,21-7,37). CONCLUSION : Le type de maison était associé à une probabilité de morbidité CCRD et CORD.
MARCO DEREFERENCIA y OBJETIVO: La exposición a los contaminantes ambientales se relaciona con el tipo de vivienda. Además del tabaquismo, la contaminación del aire en espacios cerrados representa un riesgo importante de aparición de enfermedades pulmonares crónicas (CRD). Se estudió la prevalencia de CRD en diferentes tipos de vivienda en Ciudad Ho Chi Minh, Viet Nam.

MÉTO D O: Participaron en el estudio 1561 personas que vivían en cuatro tipos de vivienda. Se obtuvo información sobre la salud respiratoria, la función pulmonar, las características de la vivienda y las fuentes de contaminación del aire interior mediante un cuestionario y la espirometría. Los dos principales resultados sanitarios fueron las CCR sintomáticas (CCRD) y las enfermedades pulmonares obstructivas crónicas (EPOC; cociente del volumen espiratorio forzado en el primer segundo y la capacidad vital forzada <0,7). Se aplicaron regresiones logísticas binarias ajustadas con respecto a la edad, el sexo, el tiempo permanecido en el domicilio, el tabaquismo, los riesgos laborales, el antecedente de tuberculosis, la presencia de mascotas, ratas, cucarachas, humedad en las paredes, la utilización de combustibles de biomasa y el aire acondicionado.

RESULTADOS: La distribución de la prevalencia de CCRD $(24,3 \%)$ y EPOC $(5,3 \%)$ no fue equitativa en los tipos de vivienda estudiados (prueba de la $\chi^{2} ; P<$ 0,0001). La prevalencia fue igual en las casas tubo y los apartamentos. El riesgo de presentar una CCRD fue un $46 \%$ mayor en las personas que vivían en una casa alquilada, en comparación con las que residían en un apartamento. El cociente de posibilidades de EPOC fue 4,64 en las personas que vivían en una casa alquilada (IC95\% 1,97-10,5) y 2,99 en los residentes de casas rurales (IC95\% 1,21-7,37).

CONCLUSIÓn: El tipo de vivienda se asoció con la posibilidad de morbilidad por CCRD y EPOC. 
Queries for jtld-24-03-12

This article has been typeset from the submitted materials. Check proofs carefully for conversion or other inadvertent errors. Please follow the Allen Press Guide to PDF Annotation when marking revisions. Do not edit the PDF directly.

If present, queries will be listed below with corresponding numbers in the margins or may appear as PDF comments addressed to the author or editor. If a correction is desired in response to a query, mark the necessary changes directly in the proof using the appropriate annotation tool. If no change is desired, no action is necessary in response.

1. Author: Please clarify this sentence. Ed

2. Author: Please cite Supplementary Figure in text. Ed 